\title{
Developing emotional competence as a life skill among adolescents
}

\begin{abstract}
Emotional competence is an essential social skill which recognizes, interprets and responds constructively to emotions in one and others. It can be included as a life skill because it helps people to function well in their environment. It ensures the emotional and social well being of the person, satisfying third $\mathrm{SDG}^{1}$ - good health and well-being. Adolescence is a vulnerable human developmental stage. It is a period of emotional instability. In the year 2014, a study was conducted among school going adolescents of Kolhapur city regarding their level of emotional competence. The study was quasi-experimental in nature. It was a pre-post study on 127 adolescents falling under the age category of 14 to 15 years. The study was conducted over a period of 2 months. There were total 57 males and 70 females adolescents in this study. The pretraining result of the study was $22 \%$ adolescents were having low level of emotional competence, $61 \%$ were having average level of emotional competence and $17 \%$ were having high level of emotional competence. The post -training result of the study was $15 \%$ adolescents were having low level of emotional competence, $65 \%$ were having average level of emotional competence and $20 \%$ were having high level of emotional competence. Through this study, it was seen that with proper training for a considerable time can increase the level of emotional competence among adolescents. For this not only training, but also a conducive environment at home as well as school play a significant role.
\end{abstract}

Keywords: emotional competence, adolescents, life skill training
Volume 3 Issue 6 - 2018

\author{
Sanjoy Roy,' Haripriya² \\ 'Associate Professor and Director, Field Work \& Placement, \\ Department of Social Work, University of Delhi, India \\ ${ }^{2}$ Research Scholar, Department of Social Work, University of \\ Delhi, India
}

Correspondence: Sanjoy Roy, Associate Professor and Director, Field Work \& Placement, Department of Social Work, University of Delhi, India, Email sanjoyroy30@gmail.com

Received: November 29, 2018 | Published: December 19,

2018

\section{Introduction}

Life skills are competencies that help people function in their environment. According to WHO, life skills are abilities that facilitate the physical, mental and emotional well-being of an individual. Since emotional competence is a part of emotional well being, it can also be considered as one of the important life skills. Emotional competence refers to one's ability to express or release his/her inner feelings (emotions). It implies an ease around others and determines one's ability to effectively and successfully lead and express. It is described as the essential social skills to recognize, interpret, and respond constructively to emotions within one and others. As a life skill, emotional competence satisfies the following features of life skills i.e., help people function well in their environments, these are learned in sequential steps related to a person's age and developmental stage as well as learned by doing activities. How an individual manages his/her emotions, whether competently or incompetently, would be a question of immense importance in explaining the growth of personality.

\section{Review of literature}

Adolescents are the future citizens of a nation. So, it is important that for a healthy future, physical, mental and emotional well-being of the adolescents is taken care of. The National Advisory Mental Health Council ${ }^{1}$ estimates that one in ten children and adolescents suffer from mental health problems; for significant proportions of these students, social and emotional problems interfere with learning in school. ${ }^{2-4}$ The study by Ciarrochi et al. ${ }^{5}$ on 'emotional competence and willingness to seek help' revealed that people with high emotion management competence (involving both self and others) were more willing to seek help from variety of sources. They were more willing to seek help from family and friends for both emotional problems and suicidal ideation.

${ }^{1}$ Sustainable Development Goals
Sapra $^{6}$ in his study among late adolescents found that aggressive behaviour has been found to be greater in those having low level of adequate depth of feeling in general as well as in boys, low level of adequate expression and control of emotions in general, less ability to function with emotions in general, less ability to cope with problem emotions and level of encouragement of positive emotions in general. This study indicates the need to improve the level of emotional competence among adolescents. The study of Hessler and $\mathrm{Katz}^{7}$ examined the associations between emotional competence and risky behavior. Results suggested that, children with poor emotional awareness and regulation had a higher likelihood of using hard drugs. Results were consistent across the concurrent and longitudinal findings and pointed to anger as an important emotion. Findings submit that children's emotional competence may serve as a useful point of intervention to decrease risky behavior in adolescents.

Life skills include capabilities which prepare people for a better resistance to the life challenges. These skills enable individuals to behave more properly and be more flexible in the society, and promote their self-esteem. Moreover, life skills training programs have a key role in promotion of mental well-being state, merit, assertiveness, self-confidence, and responsibility of the individuals. The results of the study conducted by Kazmee et al. ${ }^{8}$ in 2013 , indicated that training of life skills has been positively affected on communication skills. Nabors et al. (2000) found out training of life skills leads decrease in aggression, depression and increase in self-confidence skills and responsibility. The investigation by Kotsuo et al. ${ }^{9}$ about the possibility of increasing emotional competence among adulthood and whether this improvement results in better mental, physical and social adjustments, lead to a positive result. The investigation found that emotional competence can be increased as well as that the improvement leads to enhanced subjective and physical well-being as well as improved quality of social and emotional relationships in the intervention group. 
In a large-scale mental health study, adolescents who participated in 24 emotional intelligence training sessions over two years, had higher emotional intelligence and experienced less depression and social stress compared to adolescents in a non-random assignment control group..$^{10}$ In nutshell, emotional competence as a life skill have produced the following effects: lessened violent behaviour; decreased negative, self-destructive behaviour; increased the ability to plan ahead and choose effective solutions to problems; improved social and emotional adjustment; improved classroom behaviour; gains in self control and handling of interpersonal problems and coping with anxiety; and improved constructive conflict resolution with peers, impulse control and popularity.

\section{Objectives of the research study}

a. To know the level of emotional competence among the respondents.

b. To conduct the training programme for developing the emotional competence as a life skill.

c. To post-test the level of emotional competence among the respondents.

d. To identify factors affecting emotional competence

\section{Research methodology}

The study was conducted in the year 2014, among 127 adolescents of ninth standard who were selected using simple random sampling method from the 640 ninth standard adolescents of 'The New Model English School', Kolhapur. It was a pre and post study.

It was quasi experimental nature.

For the study, the revised Emotional Competencies Scale developed by Dr. H.C.Sharma and Dr.R.L.Bharadwaj (2007), and a personal data sheet covering questions regarding demographic and family background was used. The five components of the scale are as follows:

1. Adequate Depth of Feeling (ADF)-It refers to a feeling of being confident or capable with all reality assumptions, specifically associated with effective judgement and personality integration, which ensures vigorous participation in living.

2. Adequate Expression and Control of Emotions (AECE)-It refers to a tendency marked by adequate emotional expressiveness based on fulsome expression and control of emotions. Any form of inadequacy in either expression or control of emotion may lead to uncontrolled and disorganized emotionality.

3. Ability to Function with Emotions (AFE)-It refers to a characteristic pattern of emotional reactivity which helps the person amidst highly emotional situation to be able to maintain adequate mode of functioning that is performing actions of daily routine properly.

4. Ability to Cope with Problem Emotions (ACPE)-It refers to the understanding the role of sensitivity and the detrimental effects of problematic emotions in the beginning itself and also developing the ability to resist their harmful effects, thereafter.

5. Enhancement of Positive Emotions (EPE)-It refers to the competency of the person to develop a predominance of positive emotions in his/her personality to ensure a meaningful and fairly integrated life.

The reliability of the scale has been derived by the developers of the scale by employing two methods, namely, test-retest method (.74) and split-half method (.76). The validity of this scale has been determined using factors ADF and AFE with 16 personality factor questionnaire and found to be .64 and .69 respectively.

\section{Data collection process}

In the beginning of the study, adolescents were first given orientation about how to fill the personal data sheet and the EC-scale after which they filed it. The filled up personal data sheet and ECscales were then collected. Two days per week, researcher conducted emotional competence training programme. Totally for 10 days the training programme was conducted. The training program included discussions, experience sharing and games to enhance positive feelings, motivational stories, situation analysis and activities to introspect personal blessings to enhance positive feelings. After the completion of the training, the EC-scale was re-administered to the respondent group.

\section{Data analyses and interpretation}

Both the pre and post training responses were scored and put to statistical analyses and results were prepared accordingly. The collected data were scrutinized, tabulated and analyzed using SPSS 11.

\section{Limitations of the Study}

Since adolescents are a large group, the sample for the study is comparatively small. However it still gives an indication of the reality at a larger level. The training programme needed more time to bring better results, so it can also be taken as a limitation of the study.

\section{Major findings}

In this study, there was no significant relation found between emotional competence and religion, order of birth, parents' educational qualification, parents' occupation, place of residence (rural or urban) and type of family (nuclear or joint family). Before the intervention, there was no significant factor included in the study found to be affecting the emotional competence level of the respondents. But after the intervention some factors were identified as significant in effecting the level of emotional competence which are represented in the following tables (Table 1).

Table I Mean and standard deviation of emotional competence based on family whose feelings are easily hurt and corresponding ' $t$ ' values

\begin{tabular}{llllll}
\hline $\begin{array}{l}\text { Easily hurt } \\
\text { family } \\
\text { members }\end{array}$ & & $\begin{array}{l}\text { No of } \\
\text { respondents }\end{array}$ & Mean & $\begin{array}{l}\text { Standard } \\
\text { Deviation }\end{array}$ & $\begin{array}{l}\text { 't' } \\
\text { value }\end{array}$ \\
\hline ADF & Yes & 79 & 16.48 & 3.308 & \\
& No & 48 & 18.23 & 3.52 & $-2.818^{*}$ \\
AECE & Yes & 79 & 17.97 & 2.869 & \\
& No & 48 & 19.44 & 2.542 & $-2.906^{*}$ \\
AFE & Yes & 79 & 17.78 & 3.261 & \\
& No & 48 & 19.4 & 3.394 & $-2.658^{*}$ \\
ACPE & Yes & 79 & 19.15 & 3.167 & \\
& No & 48 & 19.96 & 3.389 & -1.355 \\
EPE & Yes & 79 & 25.71 & 2.548 & \\
& No & 48 & 25.25 & 3.139 & 0.9 \\
EC & Yes & 79 & 97.1 & 9.856 & \\
& No & 48 & 102.27 & 9.353 & $-2.921^{*}$ \\
\hline
\end{tabular}

*significant at 0.05 level 
It was found that the adolescents belonging to the family where they are given the freedom to be themselves without the fear of hurting their family members, were emotionally competent than those who find it difficult to express themselves openly in their family (Table 2). In this study, it was found that males were emotionally more competent than females in the areas of ADF (adequate depth feeling) and AECE (adequate expression and control of emotions). Females were more emotionally competent in EPE (enhancement of positive emotions). There was no significant difference in the emotional competence with regard to AFE (Ability to Function with Emotion) and ACPE (Ability to Cope with Problem Emotions). However, in this study, it was establish that overall there was no significant difference in the level of emotional competence among males and females. In the table 3, mean and standard deviation of emotional competence based on encouragement to be independent in the subjects' family and corresponding 't' values after the training is depicted (Table 3).

Table 2 Mean and standard deviation of emotional competence based on the sex of the respondents and corresponding ' $t$ ' values, after the training

\begin{tabular}{llllll}
\hline Sex & & $\begin{array}{l}\text { No of } \\
\text { respondents }\end{array}$ & Mean & $\begin{array}{l}\text { Standard } \\
\text { Deviation }\end{array}$ & 't' value \\
\hline ADF & Male & 57 & 18.95 & 2.856 & \\
& Female & 70 & 17.2 & 3.206 & $3.207^{*}$ \\
AECE & Male & 57 & 20.33 & 2.966 & \\
& Female & 70 & 18.44 & 2.591 & $3.832^{*}$ \\
AFE & Male & 57 & 19.79 & 3.411 & \\
& Female & 70 & 18.6 & 3.453 & 1.941 \\
ACPE & Male & 57 & 19.88 & 3.645 & \\
& Female & 70 & 19.46 & 3.322 & 0.678 \\
EPE & Male & 57 & 23.61 & 3.217 & \\
& Female & 70 & 26 & 2.461 & $-4.734^{*}$ \\
EC & Male & 57 & 102.56 & 10.734 & \\
& Female & 70 & 99.7 & 11.912 & 1.407 \\
\hline
\end{tabular}

*significant at 0.05 leve

The ' $\mathrm{t}$ ' values of ADF, AECE, AFE, ACPE and EPE are found to be $.741,1.939,1.256, .392$ and 1,873 respectively. The ' $t$ ' value which is near to significant value but is not significant is ' $t$ ' value of AECE (Adequate Expression and Control of Emotions) which comes to be 1.939 and that of EPE( Enhancement of Positive Emotions) which comes to be 1.873 . AECE refers to a tendency marked by adequate emotional expressiveness based on fulsome expression and control of emotions. Any form of inadequacy in either expression or control of emotion may lead to uncontrolled and disorganized emotionality. After the training, it was found to be greater in those who were encouraged to be independent in the family. EPE refers to the competency of the person to develop predominance of positive emotions in his/her personality to ensure a meaningful and fairly integrated life. After the training, it was found to be greater in those who were encouraged to be independent in the family.

Overall, the 't' value of emotional competence based on encouragement of the family to be independent, has found to be 1.700 , which is insignificant but closer to significant value. Hence, based on this result the level of emotional competence is although not significantly but almost near to it, is effected by the families encouragement to be independent (Figure 1). The pre-training result of the study was $22 \%$ adolescents were having low level of emotional competence, $61 \%$ were having average level of emotional competence and $17 \%$ were having high level of emotional competence. That is out of 127 , the number of respondents falling under the category of low, average and high level of EC were 28, 77 and 22 respectively.

Table 3 Mean and standard deviation of emotional competence based on encouragement to be independent and corresponding ' $t$ ' values, after the training

\begin{tabular}{llllll}
\hline Independent & & N & Mean & Std. deviation & 't' value \\
\hline ADF & Yes & 95 & 18.11 & 3.113 & \\
& No & 32 & 17.63 & 3.338 & 0.741 \\
AECE & Yes & 95 & 19.58 & 2.628 & \\
& No & 32 & 18.44 & 3.537 & 1.939 \\
\multirow{2}{*}{ AFE } & Yes & 95 & 19.36 & 3.339 & \\
& No & 32 & 18.47 & 3.818 & 1.256 \\
ACPE & Yes & 95 & 19.72 & 3.385 & \\
& No & 32 & 19.44 & 3.732 & 0.392 \\
EPE & Yes & 95 & 25.22 & 2.979 & \\
& No & 32 & 24.06 & 3.162 & 1.873 \\
EC & Yes & 95 & 101.98 & 10.866 & \\
& No & 32 & 98.03 & 12.737 & 1.7 \\
\hline
\end{tabular}

*significant at 0.05 level

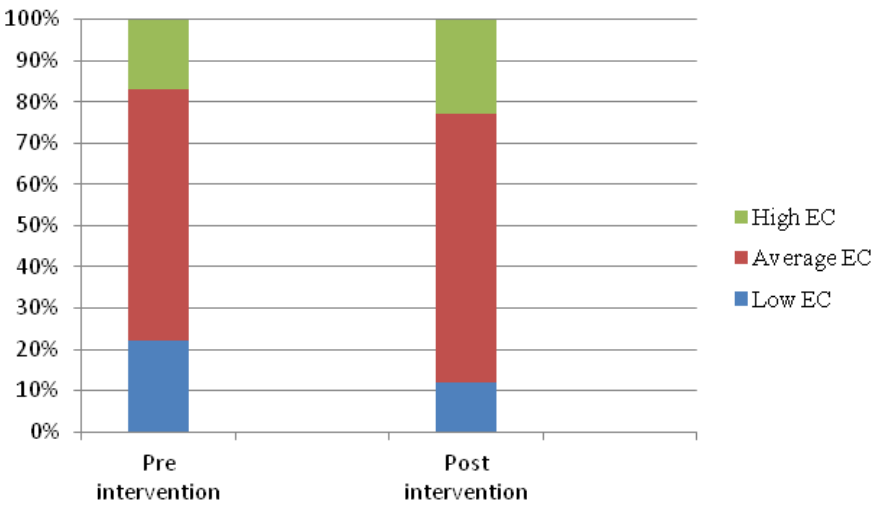

Figure I Graphical distribution of respondents based on the level of emotional competence before and after the intervention.

The post-training result of the study was $12 \%$ adolescents were having low level of emotional competence, $65 \%$ were having average level of emotional competence and $23 \%$ were having high level of emotional competence. That is out of 127, the number of respondents falling under the category of low, average and high level of EC after the training were 15,83 and 29 respectively. After the training, the level of emotional competence among the adolescents has been improved.

\section{Discussion and conclusion}

From the study, it was revealed that through proper training the level of emotional competence can be increased. For this not only training, but school and home environment both should be of nurturing nature. On a regular basis life skills training programmes 
such as focusing on emotional competence, assertiveness, personality development, should be conducted in schools. Social workers in schools or school counselors should take responsibility for conducting such programmes. In this study, even though the male respondents were having higher EC components in adequate depth, control and expression of emotions, female were having higher level of enhancement of positive emotions. Thus making the overall emotional competencies of males and females almost same.

The family in which adolescents are given opportunity to speak for self, are encouraged to be independent and where persons can share their feelings without the fear of hurting the feelings of family members create a positive environment for emotional competence. Regular parent teacher association meetings regarding the need of the adolescents and how much progress is made regarding academic as well as at personal level should be evaluated properly. Emotional competence is that life skill which promotes emotional and social well being of the person. Hence, for the assured sustainable development of the nation in the terms of good health and well being for all, it is important that their future citizen that is children and adolescents are emotionally competent. For that, the role of family and school is very pivotal. Social workers working with family and school settings can play a significant role in this regard. ${ }^{11}$

\section{Acknowledgments}

None.

\section{Conflicts of interest}

Author declares that there is no conflict of interest.

\section{References}

1. National Advisory Mental Health Council. Blueprint for change: Research on child and adolescent mental health. Report of the National Advisory Council's Workgroup on Child and Adolescent Mental Health Intervention Development and Deployment. Washington; 2001.
2. Adelman HS, Taylor L. Shaping the future of mental health in schools. Psychology in the Schools. 2000;37(1):49-60.

3. Hinshaw SP. Externalizing behavior problems and academic underachievement in childhood and adolescence: Causal relationships and underlying mechanisms. Psychological Bulletin. 1992;111(1):127-155.

4. Roeser RW, Eccles JS. Schooling and mental health. In: AJ Sameroff, M Lewis, S Miller, editors. Handbook of developmental psychopathology $\left(2^{\text {nd }} e d n\right)$. New York: Kluwer Academic/Plenum; 2000. p. 135-156.

5. Ciarrochi J, Deane F. Emotional competence and willingness to seek help from professional and non professional sources. British Journal of Guidance \& Counselling. 2001;29(2).

6. Sapra A. Aggressive behaviour as related to Emotional competencies Gender and Socio-economic status among late adolescents. Doctoral Thesis. Agra: University of Agra; 2007.

7. Hessler DM, Katz LF. Brief report: Associations between emotional competence and adolescent risky behavior. Journal of Adolescence. 2010;33(1):241-246.

8. Kazemi R, Momenia S, Abolghasemi A. The effectiveness of life skill training on self-esteem and communication skills of students with dyscalculia. Procedia-Social and Behavioral Sciences. 2013;114:863866.

9. Kotsou I, Nelis D, Grégoire J, et al. Emotional plasticity: Conditions and effects of improving emotional competence in adulthood. $J$ Appl Psychol. 2011;96:827-839.

10. Ruiz-Aranda D, Castillo R, Salguero JM, et al. Short and midterm effects of emotional intelligence training on adolescent mental health. $J$ Adolesc Health. 2012;51(5):462-467.

11. Nabors LA, Reynold MS, Weist MD. Qualitative evaluation of a high school mental health program. Journal of Youth and Adolescence. 2000;29(1):1-13. 